\title{
Macroprolactinomas and Nonfunctioning Pituitary Adenomas and Pregnancy Outcomes
}

Kimberley Lambert MBChB ${ }^{1}$, Kate Rees BSc*2, Paul T Seed MSc CStat ${ }^{2}$, Mandish K Dhanjal MBBS ${ }^{3}$, Marian Knight MBBS PhD ${ }^{4}$, David R McCance MBBS MD ${ }^{5}$, Catherine Williamson MBChB MD ${ }^{2}$

${ }^{1}$ Royal Hampshire County Hospital (RHCH), Romsey Road, Winchester, Hampshire, SO22 5DG

${ }^{2}$ Division of Women's Health, King's College London, $2^{\text {nd }}$ Floor, Hodgkin Building, Guy's Campus, London SE1 1UL

${ }^{3}$ Directorate of Maternity, Queen Charlotte's and Chelsea Hospital, Imperial College Healthcare NHS Trust, Du Cane Road, London W12 0HS

${ }^{4}$ National Perinatal Epidemiology Unit, Nuffield Department of Population Health, University of Oxford OX3 7LF, Oxford, UK

${ }^{5}$ Regional Centre for Endocrinology and Diabetes, Royal Victoria Hospital, Belfast BT12 6BA, Northern Ireland, UK

\section{Acknowledgements:}

Funded by the charity Sparks and supported by National Institute for Health Research (NIHR)

Clinical Research Facility at Guy's \& St Thomas' NHS Foundation Trust and NIHR Biomedical

Research Centre based at Guy's and St Thomas' NHS Foundation Trust and King's College London.

(CW, PS). The views expressed are those of the author(s) and not necessarily those of the NHS, the NIHR or the Department of Health.

The authors thank Leslie McMurtry for administrative support.

Abbreviated Title: Pituitary Tumors in Pregnancy

Corresponding author and person to whom reprint requests should be made:

Catherine Williamson 
Professor of Women's Health

$31 \quad 2^{\text {nd }}$ Floor, Hodgkin Building

32 Guy’s Campus

33 King's College London

34 London SE1 1UL

35

36 Phone:. +44 2078486350

37 Email: catherine.williamson@kcl.ac.uk

38 Grants: Funded by the charity Sparks and supported by National Institute for Health Research

39 (NIHR) Clinical Research Facility at Guy's \& St Thomas' NHS Foundation Trust and NIHR

40 Biomedical Research Centre based at Guy's and St Thomas' NHS Foundation Trust and King's

41 College London (CW, PS) and Tommy's charity (PS). The views expressed are those of the author(s)

$42 \quad$ Financial Disclosure

43 The authors did not report any potential conflicts of interest. 
45 Précis:

46 Macroprolactinoma and nonfunctioning pituitary adenoma can present in pregnancy with expansion

47 and apoplexy, but typically respond to medical management with good pregnancy outcomes. 


\section{Abstract}

\section{Objective}

To examine the monitoring, management, and outcomes of pituitary tumors in pregnancy.

\section{Methods}

54

A national, prospective, observational, population-based case series study was conducted in all UK consultant-led obstetric units over 3 years using the UK Obstetric Surveillance System. In order to evaluate rates of adverse pregnancy outcomes, women with a macroprolactinoma ( $\geq 10 \mathrm{~mm})$ or nonfunctioning pituitary adenoma, diagnosed before or during pregnancy, were compared to 2 comparison groups: 1) a UKOSS cohort with singleton $(\mathrm{n}=2205)$ or twin $(\mathrm{n}=27)$ pregnancy and 2$)$ data from the Office of National Statistics $(n=2,703,102)$. Main outcome measures were the incidence, management, and frequency of adverse maternal and offspring outcomes of pituitary tumors in pregnancy.

\section{Results}

There were 71 confirmed cases of pituitary tumors in pregnancy (49 macrolactinoma, 16 nonfunctioning adenomas, 3 acromegaly, 3 Cushing's disease). The women with pituitary tumors were 4 years older than comparison women $(\mathrm{P}<0.001)$. None of the 9 women treated with surgery or radiotherapy prior to pregnancy had symptomatic tumor expansion. This occurred in 6 out of 40 women with macroprolactinomas and 1 out of 7 non-functioning adenomas diagnosed before conception, and in 3 out of 5 women with non-functioning adenomas diagnosed in pregnancy. Two women had pituitary apoplexy, both of whom also had symptoms of expansion of tumor or surrounding pituitary tissue. To within the level of accuracy possible, there was no evidence that pituitary tumors were associated with adverse pregnancy outcomes (pregnancy-induced hypertension, preeclampsia, preterm labor, stillbirth). Women with non-functioning adenomas were more likely to have cesarean section compared to controls (RR 2.06, CI 1.26-3.36, $\mathrm{p}=0.035)$. 


\section{Conclusions}

76 The majority of women with macroprolactinomas and non-functioning adenomas have good

77 pregnancy outcomes. Non-functioning pituitary adenomas occur more commonly in pregnancy than

78 previously thought, and can present de novo with symptoms of pituitary expansion in pregnancy.

79

80 
Introduction

The majority of pituitary tumors in pregnant women are microprolactinomas (diameter $<10 \mathrm{~mm}$ ). Macroprolactinomas (diameter $\geq 10 \mathrm{~mm}$ ) are less common, affecting approximately $24 \%$ of pregnant women with prolactinoma [1] and the precise incidence of these tumors in pregnancy is unknown. Other pituitary tumors occur more rarely in pregnant women and may be functioning (producing growth hormone, adrenocorticotrophic hormone or thyroid stimulating hormone), or nonfunctioning pituitary adenomas.

Pregnant women with microprolactinomas typically have uncomplicated pregnancies with no symptoms of tumor enlargement [1]. Among all prolactinomas, about $46 \%$ enlarge during pregnancy [2], while symptomatic enlargement occurs less frequently. Approximately $30 \%$ of macroprolactinomas undergo symptomatic enlargement while only $3 \%$ of the more common microprolactinomas do so. If women with macroprolactinomas are treated prenatally with surgery or radiation, their risk of tumor enlargement is markedly reduced [3].

Symptoms consistent with enlargement are reported in 5 of 9 cases of nonfunctioning pituitary adenoma reported in the literature [4-7]. We identified 3 reported women with thyrotrophinomas [810]; 2 of whom had gestational tumor enlargement. Three retrospective series described 72 pregnancies in 58 women with acromegaly. Maternal complications included type 2 diabetes, gestational diabetes mellitus, pregnancy-induced hypertension and pre-eclampsia and $8 \%$ had symptomatic enlargement $[11,12]$. Combined data from 136 pregnancies in 122 women with Cushing's disease demonstrated a high rate of adverse outcomes, including preterm labor (43\%), intrauterine growth restriction (21\%), stillbirth (6\%), pre-eclampsia (14\%), diabetes or impaired glucose tolerance (25\%) [13].

The aim of this study was to describe the incidence, characteristics, management and outcomes of a UK national case series of pregnant women with pituitary tumors. 
107 
A national, prospective observational, population-based case series study was undertaken over 3 years (March 2010 to February 2013) using the UK Obstetric Surveillance System (UKOSS). UKOSS is a research platform with reporting clinicians in all UK consultant-led maternity units, designed to study rare complications of pregnancy on a national basis. UKOSS utilizes a prospective monthly case collection scheme that includes all 202 consultant-led obstetric units in the UK. Women are not contacted directly and no personally identifiable information is collected. As all women with pituitary tumors should have consultant-led care, we anticipate that the study is likely to have covered all women with pituitary tumors within the entire UK birth cohort. The study was approved by the Riverside Ethics Committee, London (reference number 09/H0706/78).

Exposed women were defined as those with macroprolactinomas $(\geq 10 \mathrm{~mm})$, nonfunctioning pituitary adenomas, Cushing's disease, acromegaly or thyrotrophinomas diagnosed before or during pregnancy. As the UKOSS system is limited to the study of rare diseases (incidence $<1$ in 2000 deliveries), women with microprolactinoma $(<10 \mathrm{~mm}$ diameter) were excluded from the study.

Women who met the criteria for the study were identified by the obstetrician or endocrinologist responsible for their care. On reporting a woman with a pituitary tumor, the clinician was asked to complete a data collection form. Anonymized data were collected about pituitary tumor diagnosis, monitoring and management before pregnancy and antenatally, as well as maternal demographics, obstetric and medical history, delivery and perinatal outcomes. Thirty eight women were excluded (Figure 1) if they did not meet the entry criteria $(n=16)$ or a data collection form was reported in error, duplicated or notes could not be found ( $\mathrm{n}=22)$. Two comparison groups were used. The first comparison group included women in an established UKOSS database with an uncomplicated singleton $(\mathrm{n}=2205)$ or twin $(\mathrm{n}=27)$ pregnancy. The UKOSS comparison group comprised pregnant women from whom data had previously been collected between February 2005 and February 2006. 
conditions under study at that time (antenatal pulmonary embolism, eclampsia or peripartum hysterectomy). They did not have the conditions being studied for UKOSS and were not matched for gestational week. Data were collected retrospectively by the UKOSS investigators from their medical charts on any complications of pregnancy they experienced. These data were collected in an identical manner to the data on exposed women through specific data collection forms completed by clinical staff; when forms were returned with invalid or out of range responses, clinicians were contacted and asked to correct the information. The control women did not have any known pituitary pathology at the time they were identified. These data were collected 5 years prior to commencement of the UKOSS Pituitary Study. Information from the Office of National Statistics in England for the years of the study was used for a second comparison group to calculate incidence rates of each tumor in pregnancy. The Office of National Statistics database is based on statutory birth and death registrations and includes the information recorded on birth and death certificates; no further validation of these data takes place. For the Office of National Statistics data we could not separate singleton and multiple pregnancies and this should be taken into account in pregnancy outcome comparisons.

The study was advertised at the UK Society for Endocrinology Annual Conference and all UK endocrinologists were contacted via email and by post to ask them to inform their local UKOSS team of any pregnant women with pituitary tumors during the study period. No additional cases were identified. The main outcome measures were the incidence, management, and frequency of adverse maternal and offspring outcomes of pituitary tumors in pregnancy.

Statistical analysis was performed using Stata version 12.1 [14]. P values were considered significant if $\leq 0.05$. Women with multiple pregnancies were included in comparisons of sociodemographic data, and to calculate the incidence of pituitary tumors in the UK, but women with multiple pregnancies were excluded from the UKOSS control group for pregnancy outcome comparisons, as this group has an increased risk of both maternal and neonatal adverse outcomes. For Office of National Statistics 
control data it was not possible to remove multiple pregnancies from the dataset. Incidence rates were estimated with $95 \% \mathrm{CI}$. Adjustment for variables such as maternal age or occupation was not possible for comparison of adverse pregnancy outcomes due to small numbers ( $\mathrm{n}<8$ for all outcomes). Presence or absence of tumor expansion was compared between different disease groups using Fisher's exact test. For categorical data, unadjusted risk ratios (RR) [15] were used with Fisher's exact $\mathrm{p}$ values (more appropriate for small sample sizes), and risk differences (RD). For continuous data, mean differences and t-tests were calculated [16]. No woman included in the analysis had data included from repeat pregnancies.

\section{Results}

During the 3 year study period there were 71 confirmed cases of the pituitary tumors included in this study in pregnant women (Figure 1). There were 2,703,102 maternities (defined as women giving birth to one or more live born or stillborn babies after 24 weeks' gestation) in the UK in the same study period (from March 2010 to February 2013). The estimated incidence of each of the tumors in pregnant women is shown in Table 1. As the majority of women identified had macroprolactinomas and non-functioning pituitary tumors the principal focus of the study relates to these cases. There were 3 cases of Cushing's disease, and 3 of acromegaly that were not included in subsequent analysis. Only one of these 6 women had a normal delivery at term, the other 5 pregnancies resulted in either surgical termination, ectopic pregnancy, or unexplained stillbirth.

Affected women were more likely to be older than UKOSS controls (Mean difference 4.06, CI 2.76 to 5.36, $\mathrm{p}<0.001)$ (Table 2). There were no differences in ethnic group or BMI.

The presenting symptoms differed between women with macroprolactinoma and nonfunctioning pituitary adenoma (Figure 2). Ninety eight percent (48/49) of macroprolactinomas and 75\% (12/16) of nonfunctioning pituitary adenomas were identified prior to pregnancy. Women with a macroprolactinoma were more likely to present with symptoms of hormone excess such as 
amenorrhoea (RR 5.06 CI 1.36-18.8, p<0.001) and galactorrhoea (RR 2.45 CI 0.63-9.6, p = 0.20). In contrast, women with nonfunctioning pituitary adenoma were more likely to present with clinical features consistent with tumor mass expansion such as visual symptoms (RR 4.59, CI 1.48-14.3, p = $0.011)$.

There were 10 cases with tumor expansion in pregnancy; 6 had a macroprolactinoma and 4 a nonfunctioning pituitary adenoma (Table 3). Apart from previous treatment with surgery, radiotherapy or both, there were no significant factors in the demographic or previous obstetric features to predict tumor expansion. Of the 60 women in whom a macroprolactinoma or nonfunctioning pituitary adenoma was diagnosed prior to pregnancy, 9 had undergone surgery, radiotherapy or both prior to pregnancy. None of this group had tumor expansion during pregnancy. Of the remaining 51 patients who did not have surgery or radiotherapy prior to pregnancy $7(13.7 \%)$ had tumor expansion, 6 of whom had symptoms (Table 3). All the macroprolactinoma cases with symptomatic expansion were diagnosed prior to pregnancy, while only 1 of the 4 cases of nonfunctioning pituitary adenoma with symptoms of tumor expansion was diagnosed pre-pregnancy.

There was no significant difference in the size of the macroprolactinoma prior to conception in those who did or did not have symptomatic tumor expansion (mean diameter $13.8 \mathrm{~mm}$ compared to 13.0 $\mathrm{mm}$, respectively). The symptoms reported in association with tumor expansion included headache, visual impairment and neurological impairment (Table 3).

In the entire case series, 17 women had symptoms (11 out of 49 macroprolactinomas and 6 out of 16 nonfunctioning pituitary adenomas) suggestive of tumor expansion (headache, visual field changes or specific neurological symptoms as described in Table 3). The majority (80\%, CI 51.9-96) of the cases with symptoms had further investigation with formal visual field testing. A larger proportion of women with macroprolactinomas (75.5\%; CI 61.1-87) had formal visual field tests performed during pregnancy than women with nonfunctioning pituitary adenoma (56.3\%; CI 29.9-80) (RR 1.34, CI $0.85-2.13, \mathrm{p}=0.21)$. There was no difference in the proportion of women with macroprolactinoma or nonfunctioning pituitary adenoma that had impaired visual fields. 
211 Of the 60 women diagnosed prior to pregnancy, 46 out of 48 (95.9\%, CI 86.0-99.5) with a

212 macroprolactinoma and none of the women with a nonfunctioning pituitary adenoma received

213 medical treatment before they conceived (Table 4). Cabergoline was the most likely dopaminergic

214 drug to be prescribed to those with macroprolactinoma prior to pregnancy. It was prescribed to 32

215 women $(65.3 \%$, CI 50.4-78.3) compared to bromocriptine 10 (20.4\%, CI 10.2-34.3) or quinagolide 4

$216(8.2 \%$, CI 2.3-19.6). Nineteen women stopped taking cabergoline before the end of the first trimester

217 as did 5 women treated with bromocriptine. Eighteen women with a macroprolactinoma continued

218 medication during the first trimester of pregnancy.

219 A larger proportion of women with macroprolactinoma had dopamine agonists prescribed during 220 pregnancy $(47 \%$, CI 32-62), compared to only $12.5 \%$ of those with nonfunctioning pituitary adenoma

221 (CI 1.6-38), (RR 3.76, CI 0.99-14.2, p = 0.018). Only 6 of the 49 women with a macroprolactinoma

222 took dopamine agonists throughout the entire pregnancy; 1 was treated with bromocriptine and 5 took

223 cabergoline. Seven women (5 with macroprolactinoma and 2 with nonfunctioning pituitary adenoma)

224 started taking dopamine agonists de novo in pregnancy. Of the 2 women with nonfunctioning pituitary

225 adenoma, one started taking cabergoline in the $2^{\text {nd }}$ trimester and one in the $3^{\text {rd }}$ trimester.

226 Of the 15 women with symptoms suggestive of tumor enlargement, 6 (40\%, CI 16.3-67.7) were

227 prescribed dopamine agonists in the first trimester.

228 The pregnancy outcome data are only presented for singleton pregnancies due to the known increased 229 risk of adverse outcomes with multiple pregnancies [17]. Overall women with macroprolactinoma or 230 nonfunctioning pituitary adenoma in pregnancy did not have increased rates of adverse outcomes 231 (preterm birth, pregnancy-induced hypertension, pre-eclampsia or stillbirth) compared to controls 232 (Table 5).

233 Women with nonfunctioning pituitary adenoma had significantly more cesarean deliveries (50\%) than both UKOSS (23\%) (RR 2.14, CI 1.31-3.52, p = 0.032) and Office of National Statistics controls, i.e. those from the national comparison group $(24 \%)(\mathrm{RR} 2.06, \mathrm{CI} 1.26-3.36, \mathrm{p}=0.035)$. In contrast, women with macroprolactinoma were no more likely to have cesarean deliveries (27\%) 
237 compared to UKOSS controls (RR 1.14, CI 0.71-1.82, $\mathrm{p}=0.61)$ or ONS controls $(23 \%$ vs $24 \%)$ (RR

$2381.09, \mathrm{CI} 0.68-1.74, \mathrm{p}=0.74)$. Women with macroprolactinoma or nonfunctioning pituitary adenoma

239 were more likely to have induction of labor than Office of National Statistics controls (37\% and $44 \%$

240 respectively vs $20 \%$ of controls) (RR 1.95 , CI $1.44-2.66 \mathrm{p}<0.001)$.

241 Of the 10 women who had tumor expansion in pregnancy, 4 had spontaneous vaginal

242 deliveries, one had an induction of labor and vaginal delivery, and 5 had cesarean

243 deliveries. Of these 5 women, only 2 cesarean deliveries were for symptoms associated with

244 raised intracranial pressure: 1 was due to worsening vision, diabetes insipidus and pre-

245 eclampsia, and another woman had pituitary apoplexy. The other cesarean deliveries were

246 performed as a consequence of failed induction, and maternal request following previous

247 cesarean delivery..

248 The numbers were too small in the exposed group of pregnant women to be able to make a

249 robust statement about the risk of birth defects. 


\section{Discussion}

253 This large prospective UK case series study of macroprolactinomas and nonfunctioning pituitary

254 adenomas in pregnant women has provided valuable insights into the presentation, course and

255 management of these tumors. One advantage of a case series drawn from a national cohort of known

256 size is that it provides a more accurate estimate of the incidence of these rare tumors in pregnancy.

257 Nonfunctioning pituitary adenoma is the second most frequently occurring pituitary macroadenoma in

258 the non-pregnant population and therefore it is surprising that so few cases in pregnancy have been

259 documented. In our study women with pituitary macroadenomas in pregnancy were likely to be older

260 than control women.

261 The pituitary gland normally increases in size in pregnancy as a likely consequence of estrogen-

262 stimulated hyperplasia and hypertrophy of lactotroph cells $[18,19]$. This prospective UK study

263 identified a lower rate of symptomatic macroprolactinoma expansion during pregnancy than has

264 previously been reported [3]. This may be because 94\% (46 out of 49) of women with a

265 macroprolactinoma took a dopamine agonist prior to pregnancy, and 39\% (18 out of 46) continued it

266 during the first trimester. The preferred dopamine agonist was cabergoline. The relatively high

267 proportion of women that continued dopamine agonists is similar to the findings of a study that

268 questioned endocrinologists about how they would manage these cases; $82 \%$ stated that they would

269 continue treatment in women with large macroprolactinomas [20]. Many endocrinologists continue

270 dopamine agonists in women with large macroprolactinomas, consistent with guidelines of the

271 Pituitary Society [21] and the Endocrine Society [22] (summarised in Box 2). However the British

272 Medicine and Healthcare Products Advisory Authority guidance in 2008 recommended stopping

273 cabergoline 1 month prior to pregnancy due to concern about cardiac fibrosis [23]. Thus, current

274 practice may reflect the fact that most clinicians are likely to be more concerned about the risks of

275 tumor enlargement than unsubstantiated theoretical risks of cardiac fibrosis. It is encouraging that this 
prospective study demonstrated no cases of symptomatic macroprolactinoma enlargement in women previously treated with surgery or radiotherapy, consistent with previous reports [3].

The Pituitary Society guidance on management of macroprolactinomas in pregnancy recommends close surveillance if dopamine agonists have been stopped [21], and The Endocrine Society recommends that for women with a macroprolactinoma who have not undergone pituitary surgery, "it is prudent to undertake more frequent clinical examination and formal visual field testing" [22]. The Society's guidance has never been prospectively evaluated. In our study $75 \%$ of women with macroprolactinomas and 56\% (9 out of 16) with nonfunctioning pituitary adenoma had a formal visual field test performed at least once during the pregnancy. However, only $33 \%$ of women with macroprolactinoma had visual fields monitored in each trimester. It is possible that some cases of tumor expansion might have been identified prior to onset of symptoms if surveillance had been performed more regularly.

There were two UKOSS cases of pituitary apoplexy. One had a macroprolactinoma and the other nonfunctioning pituitary adenoma, and both were diagnosed as having pituitary tumors prior to pregnancy. Both cases were managed conservatively with good outcomes. This is a rare, serious complication of pituitary adenoma in pregnancy and to date only 15 cases have been reported in the literature (PubMed search, keywords: pregnancy, pituitary, tumor, non-functioning, macroprolactinoma, acromegaly, Cushing, TSHoma, apoplexy, cabergoline, bromocriptine, quinagolide, pegvisomont, somatostatin analogue, octreotide, lanreotide; dates: 1985-2015) [6]. Most cases were not diagnosed as having a pituitary tumor until they presented with apoplexy in pregnancy. Box 1 summarises the symptoms of pituitary apoplexy and of pituitary tumor expansion in pregnant women reported in the literature and in the current study.

There was no increase in the rate of congenital malformations associated with dopamine agonist use in the first trimester. Although this is consistent with the current literature [2, 24, 25], the current 
303

304

305

306

307

308

309

310

311

312

313

314

315

316

317

318

319

320

321

322

study was not powered to detect a difference. Similarly, women with macroprolactinoma or nonfunctioning pituitary adenoma in pregnancy did not have increased rates of preterm labor, hypertensive disease, pre-eclampsia or fetal loss.

Potential limitations of this study include the fact that microprolactinomas were not included.

Unfortunately this was not possible as they were too common to include in a UKOSS study of rare disorders of pregnancy. It would have been valuable to establish whether the findings in macroprolactinomas can be generalized to all prolactinomas. Some cases may have been missed if they were managed by neurologists or neurosurgeons, and a future study could benefit from also writing to these specialists to ensure all UK cases were identified.

In summary, the majority of women with macroprolactinoma and nonfunctioning pituitary adenoma have good pregnancy outcomes, although pituitary apoplexy occurred in one woman with each type of tumor. This study demonstrates that nonfunctioning pituitary adenoma occurs more commonly in pregnancy than previously thought, and that this group of tumors can present de novo with symptoms of expansion. Ergot-containing dopamine agonists, particularly cabergoline, were the treatment of choice most frequently used for symptomatic expansion of pituitary tumors, and the majority of women with symptoms suggestive of tumor expansion can be successfully treated without surgery. A significant number of clinicians elect to continue or restart dopaminergic therapy during pregnancy in women with macroprolactinomas, consistent with national guidelines. 
1. Molitch, M.E., Endocrinology in pregnancy: management of the pregnant patient with a

prolactinoma. Eur J Endocrinol, 2015. 172(5): p. R205-13.

2. Lebbe, M., et al., Outcome of 100 pregnancies initiated under treatment with cabergoline in hyperprolactinaemic women. Clin Endocrinol (Oxf), 2010. 73(2): p. 236-42.

3. Molitch, M.E., Pituitary tumors and pregnancy. Growth Horm IGF Res, 2003. 13 Suppl A: p. S38-44.

4. Kupersmith, M.J., C. Rosenberg, and D. Kleinberg, Visual loss in pregnant women with pituitary adenomas. Ann Intern Med, 1994. 121(7): p. 473-7.

5. Masding, M.G., et al., Visual field compression by a non-secreting pituitary tumour during pregnancy. J R Soc Med, 2003. 96(1): p. 27-8.

6. Kita, D., et al., Postoperative diabetes insipidus associated with pituitary apoplexy during pregnancy. Neuro Endocrinol Lett, 2012. 33(2): p. 107-12.

7. de Heide, L.J., K.M. van Tol, and B. Doorenbos, Pituitary apoplexy presenting during pregnancy. Neth J Med, 2004. 62(10): p. 393-6.

8. Chaiamnuay, S., et al., Successful management of a pregnant woman with a TSH secreting pituitary adenoma with surgical and medical therapy. Pituitary, 2003. 6(2): p. 109-13.

9. Blackhurst, G., et al., The treatment of a thyrotropin-secreting pituitary macroadenoma with octreotide in twin pregnancy. Clin Endocrinol (Oxf), 2002. 57(3): p. 401-4.

10. Caron, P., et al., Successful pregnancy in an infertile woman with a thyrotropin-secreting macroadenoma treated with somatostatin analog (octreotide). J Clin Endocrinol Metab, 1996. 81(3): p. 1164-8.

11. Cheng, S., et al., Pregnancy in acromegaly: experience from two referral centers and systematic review of the literature. Clin Endocrinol (Oxf), 2012. 76(2): p. 264-71.

12. Caron, P., et al., Acromegaly and pregnancy: a retrospective multicenter study of 59 pregnancies in 46 women. J Clin Endocrinol Metab, 2010. 95(10): p. 4680-7.

13. Lindsay, J.R., et al., Cushing's syndrome during pregnancy: personal experience and review of the literature. J Clin Endocrinol Metab, 2005. 90(5): p. 3077-83.

14. StataCorp, College Station, Texas.

15. Rotherman, K.J., Modern Epidemiology. Boston, Little Brown. 1986.

16. Satterwaite, F.E., An approximate distribution of estimates of variance components. Biometrics Bulletin, 1946. 2: p. 110-114.

17. Doyle, P., The outcome of multiple pregnancy. Hum Reprod, 1996. 11 Suppl 4: p. 110-7; discussion 118-20.

18. Goluboff, L.G. and C. Ezrin, Effect of pregnancy on the somatotroph and the prolactin cell of the human adenohypophysis. J Clin Endocrinol Metab, 1969. 29(12): p. 1533-8.

19. Scheithauer, B.W., et al., The pituitary gland in pregnancy: a clinicopathologic and immunohistochemical study of 69 cases. Mayo Clin Proc, 1990. 65(4): p. 461-74.

20. Almalki, M.H., et al., Management of prolactinomas during pregnancy -- a survey of four Canadian provinces. Clin Invest Med, 2012. 35(2): p. E96-104.

21. Casanueva, F.F., et al., Guidelines of the Pituitary Society for the diagnosis and management of prolactinomas. Clin Endocrinol (Oxf), 2006. 65(2): p. 265-73.

22. Melmed, S., et al., Diagnosis and treatment of hyperprolactinemia: an Endocrine Society clinical practice guideline. J Clin Endocrinol Metab, 2011. 96(2): p. 273-88.

23. Medicines and Healthcare Products Regulatory Agency. Drug safety update, 2008. 2(3).

24. Colao, A., et al., Pregnancy outcomes following cabergoline treatment: extended results from a 12-year observational study. Clin Endocrinol (Oxf), 2008. 68(1): p. 66-71.

25. Robert, E., et al., Pregnancy outcome after treatment with the ergot derivative, cabergoline. Reprod Toxicol, 1996. 10(4): p. 333-7. 
Table 1: Incidence of Pituitary Tumors in Pregnant women in the UK

\begin{tabular}{|lll|}
\hline Tumor Type & $\begin{array}{l}\text { Number of pregnancies } \\
\text { identified in UKOSS study }\end{array}$ & $\begin{array}{l}\text { Incidence in pregnancy- } \\
\text { cases per 100,000 } \\
\text { maternities } \\
(\mathbf{9 5 \%} \mathrm{Cl})\end{array}$ \\
\hline \hline Macroprolactinoma & 49 & $1.80(1.30-2.40)$ \\
\hline $\begin{array}{l}\text { Non-functioning pituitary } \\
\text { adenoma }\end{array}$ & 16 & $0.59(0.34-0.96)$ \\
\hline Acromegaly & 3 & $0.11(0.02-0.32)$ \\
\hline Cushing's disease & $3^{1}$ & $0.11(0.02-0.32)$ \\
\hline $\begin{array}{l}\text { Thyrotropin secreting } \\
\text { pituitary adenoma }\end{array}$ & 0 & $0.00(0.00-0.13)$ \\
\hline
\end{tabular}

374

$375{ }^{1}$ One woman with Cushing's disease had 2 pregnancies within the UKOSS study time span.

$376 *$ Denotes not possible to determine 
Table 2. Sociodemographic characteristics of women with rare pituitary tumors in pregnancy and healthy controls.

\begin{tabular}{|c|c|c|c|}
\hline & $\begin{array}{l}\text { Macroprolactinoma } \\
\mathrm{N}=49\end{array}$ & $\begin{array}{l}\text { Nonfunctioning Pituitary } \\
\text { Adenoma } \\
\mathrm{N}=16\end{array}$ & $\begin{array}{l}\text { UKOSS control } \\
N=2250\end{array}$ \\
\hline$\frac{\text { Age }}{\text { Mean (SD) }}$ & $33.6(5.2)$ & $31.6(5.0)$ & $29.1(6.1)$ \\
\hline $\begin{array}{l}<30 \\
\text { no. (\%) }(95 \% \mathrm{Cl})\end{array}$ & $11(22.4)(11.8-36.6)$ & $5(31.3)(11.0-58.7)$ & $1133(50.4)(48.3-52.4)$ \\
\hline 30-35 & $17(34.7)(21.7-49.6)$ & $6(37.5)(15.2-64.6)$ & $620(27.5)(25.7-29.5)$ \\
\hline$>35$ & $21(42.9)(28.8-57.8)$ & $5(31.3)(11.0-58.7)$ & $497(22.1)(20.4-23.9)$ \\
\hline $\begin{array}{l}\text { Ethnic group } \\
\text { no. (\%) }(95 \% \mathrm{Cl}) \\
\text { White }\end{array}$ & 36 (73.5) (58.9-85.1) & 15 (93.8) (69.8-99.8) & $1793 / 2172(82.6)(80.9-84.1)$ \\
\hline Black & 6 (12.2) (4.6-2.5) & 0 & $115 / 2172(5.3)(4.4-6.3)$ \\
\hline Asian & $5(10.2)(3.4-22.2)$ & 0 & 195/2172 (9.0) (7.8-10.3) \\
\hline Not known & $2(4.1)(0.5-14.0)$ & $1(6.3)(0.16-30.2)$ & $44 / 2172(2.0)(1.4-2.6)$ \\
\hline Mixed & 0 & 0 & $25 / 2172(1.2)(0.75-1.7)$ \\
\hline Non white & $11(22.4)(11.8-36.6)$ & 0 & $335 / 2172$ (15.4) (13.9-17.0) \\
\hline$\frac{\text { BMI }}{\text { Mean (SD) }}$ & $27.3(6.8)$ & $25.2(5.9)$ & $25.7(5.5)$ \\
\hline $\begin{array}{l}<18 \\
\text { no. (\%) }(95 \% \mathrm{Cl})\end{array}$ & 0 & 0 & $30(1.3)(0.90-1.9)$ \\
\hline $18-24.9$ & 22 (44.9) (30.7-59.8) & $8(50)(24.7-75.3)$ & $1089(48.4)(46.3-50.5)$ \\
\hline 25-29.9 & $9(18.4)(8.8-32.0)$ & $3(18.8)(4.05-45.6)$ & $543(24.1)(22.4-26.0)$ \\
\hline 30-34.9 & $11(22.4)(11.8-36.6)$ & $2(12.5)(1.6-38.3)$ & 228 (10.1) (8.9-11.5) \\
\hline$>35$ & $7(14.3)(5.9-27.2)$ & $3(18.8)(4.05-45.6)$ & 360 (16) (14.5-17.6) \\
\hline
\end{tabular}


Table 3: Clinical details of cases that underwent tumor expansion in pregnancy

\begin{tabular}{|c|c|c|c|c|c|c|c|c|c|c|c|}
\hline \multirow[t]{3}{*}{ Diagnosis Type } & \multicolumn{4}{|l|}{ Pre-Pregnancy } & \multicolumn{7}{|c|}{ Pregnancy } \\
\hline & \multirow[t]{2}{*}{ Medication } & \multirow{2}{*}{$\begin{array}{l}\text { Length of } \\
\text { time on } \\
\text { medication } \\
\text { prior to } \\
\text { pregnancy } \\
\text { (months) }\end{array}$} & \multirow{2}{*}{$\begin{array}{l}\text { Reduced } \\
\text { visual } \\
\text { fields }\end{array}$} & \multirow{2}{*}{$\begin{array}{l}\text { Trimester } \\
\text { of tumor } \\
\text { expansion }\end{array}$} & \multirow{2}{*}{$\begin{array}{l}\text { Increase } \\
\text { in size } \\
(\mathrm{cm})\end{array}$} & \multirow{2}{*}{$\begin{array}{l}\text { Extension } \\
\text { beyond } \\
\text { sella } \\
\text { turcica }\end{array}$} & \multicolumn{3}{|c|}{ Visual field testing } & \multirow{2}{*}{$\begin{array}{l}\text { Presenting } \\
\text { symptoms }\end{array}$} & \multirow{2}{*}{$\begin{array}{l}\text { Management } \\
\text { (trimester) }\end{array}$} \\
\hline & & & & & & & $\begin{array}{l}1^{\text {st }} \\
\text { trimester }\end{array}$ & $\begin{array}{l}2^{\text {nd }} \\
\text { trimester }\end{array}$ & $\begin{array}{l}3^{\text {rd }} \\
\text { trimester }\end{array}$ & & \\
\hline MP & No & 36 & NK & $2^{\text {nd }}$ & 0.3 & NK & 2 & 2 & NP & $\begin{array}{l}\text { Clinical notes } \\
\text { indicate likely } \\
\text { visual defect }\end{array}$ & $\begin{array}{l}\text { Cabergoline (2 and } 3 \text { ) } \\
\text { Bromocriptine (2) }\end{array}$ \\
\hline MP & Bromocriptine & 2 & Yes & $1^{\text {st }}$ & 1.4 & Yes & 3 & 3 & 3 & $\begin{array}{l}6^{\text {th }} \text { nerve } \\
\text { palsy } \\
\text { Left } 3^{\text {rd }}, 4^{\text {th }} \\
\text { and } 6^{\text {th }} \text { nerve } \\
\text { palsy }\end{array}$ & $\begin{array}{l}\text { Bromocriptine (1) } \\
\text { Cabergoline (2) }\end{array}$ \\
\hline MP & Cabergoline & 5 & No & $2^{\text {nd }}$ & 0.8 & No & 1 & NP & $\mathrm{NP}$ & Headache & Cabergoline $(1,2,3)$ \\
\hline MP & Cabergoline & 48 & No & $3^{\text {rd }}$ & 0.0 & Yes & 1 & 2 & 3 & $\begin{array}{l}\text { Deterioration } \\
\text { in visual } \\
\text { fields }^{+}\end{array}$ & Cabergoline $(1,2,3)$ \\
\hline MP & Cabergoline & 12 & No & $2^{\text {nd }}$ & 0.7 & No & 1 & 1 & 1 & $\begin{array}{l}\text { Headache } \\
\text { Haemorrhage } \\
\text { into tumor } \\
\text { on MRI }\end{array}$ & Dexamethasone (2) \\
\hline Macroprolactinoma & $\begin{array}{l}\text { Cabergoline } \\
\text { Levothyroxine }\end{array}$ & 2 & NK & $3^{\text {rd }}$ & 1.2 & NK & 3 & NP & NP & $\begin{array}{l}\text { Blurred } \\
\text { Vision }\end{array}$ & $\begin{array}{l}\text { Cabergoline (1) } \\
\text { Bromocriptine (3) }\end{array}$ \\
\hline $\begin{array}{l}\text { Nonfunctioning } \\
\text { pituitary adenoma }\end{array}$ & NA & $\mathrm{DP}$ & --- & $3^{\text {rd }}$ & $\mathrm{NA}$ & No & NP & $\mathrm{NP}$ & NP & $\begin{array}{l}\text { Focal } \\
\text { neurology }\end{array}$ & No \\
\hline $\begin{array}{l}\text { Nonfunctioning } \\
\text { pituitary adenoma }\end{array}$ & No & 48 & Yes & $2^{\text {nd }}$ & NK & No & 2 & 2 & 2 & $\begin{array}{l}\text { Headache } \\
\text { Pituitary } \\
\text { apoplexy }\end{array}$ & Cabergoline (2) \\
\hline Nonfunctioning & NA & DP & --- & $2^{\text {nd }}$ & NA & NK & NP & NP & NP & Visual loss & Surgery \\
\hline
\end{tabular}




\begin{tabular}{|c|c|c|c|c|c|c|c|c|c|c|c|}
\hline pituitary adenoma & & & & & & & & & & & \\
\hline $\begin{array}{l}\text { Nonfunctioning } \\
\text { pituitary adenoma }\end{array}$ & NA & $\mathrm{DP}$ & $\begin{array}{l}-- \\
\end{array}$ & $3^{\text {rd }}$ & NA & Yes & 1 & 1 & 1 & $\begin{array}{l}\text { Absence } \\
\text { episodes }\end{array}$ & Cabergoline (3) \\
\hline
\end{tabular}

NA: not applicable; NK: information not known; DP: diagnosed in pregnancy; NP: not performed

* Diagnosed during pregnancy

+Visual fields improved following cabergoline treatment

Visual field assessment; 1: normal; 2: abnormal; 3: worsening of defect 


\begin{tabular}{|c|c|c|c|}
\hline & $\begin{array}{l}\text { Macroprolactinoma } \\
\mathrm{N}=49\end{array}$ & $\begin{array}{l}\text { Macroprolactinoma that } \\
\text { expanded } \\
\mathrm{N}=6\end{array}$ & $\begin{array}{l}\text { Nonfunctioning pituitary } \\
\text { adenoma } \mathrm{N}=16\end{array}$ \\
\hline $\begin{array}{l}\text { Women prescribed } \\
\text { dopamine agonist }\end{array}$ & $46(95.9, \mathrm{Cl} 86.0-99.5)$ & $5(83.3, \mathrm{Cl} 35.8-99.6)$ & $2(12.5, \mathrm{Cl} 1.6-38.3)$ \\
\hline $\begin{array}{l}\text { Cabergoline } \\
\text { Pre pregnancy } \\
1^{\text {st }} \text { trimester } \\
2^{\text {nd }} \text { trimester } \\
3^{\text {rd }} \text { trimester }\end{array}$ & $\begin{array}{l}32(65.3, \mathrm{Cl} 50.4-78.3) \\
13(26.5, \mathrm{Cl} 14.9-41.1) \\
9(18.4, \mathrm{Cl} 8.8-32.0) \\
7(14.3, \mathrm{Cl} 5.9-27.2)\end{array}$ & $\begin{array}{l}4(66.7, \mathrm{Cl} 22.3-95.7) \\
3(20.4, \mathrm{Cl} 11.8-88.2) \\
4(66.7, \mathrm{Cl} 22.3-95.7) \\
3(20.4, \mathrm{Cl} 11.8-88.2)\end{array}$ & $\begin{array}{l}0(0.0, \mathrm{Cl} 0.0-21.0) \\
0(0.0, \mathrm{Cl} 0.0-21.0) \\
1(6.3, \mathrm{Cl} 0.16-30.2) \\
1(6.3, \mathrm{Cl} 0.16-30.2)\end{array}$ \\
\hline $\begin{array}{l}\text { Bromocriptine } \\
\text { Pre pregnancy } \\
1^{\text {st }} \text { trimester } \\
2^{\text {nd }} \text { trimester } \\
3^{\text {rd }} \text { trimester } \\
\text { Quinagolide } \\
\text { Pre pregnancy } \\
1^{\text {st }} \text { trimester } \\
2^{\text {nd }} \text { trimester } \\
3^{\text {rd }} \text { trimester }\end{array}$ & $\begin{array}{l}10(20.4, \mathrm{Cl} 10.2-34.3) \\
5(10.2, \mathrm{Cl} 3.4-22.2) \\
4(8.2, \mathrm{Cl} 2.3-19.6) \\
3(6.1, \mathrm{Cl} 1.3-16.9) \\
\\
4(8.2, \mathrm{Cl} 2.3-19.6) \\
2(4.1, \mathrm{Cl} 0.50-14.0) \\
0(0.0 \%, \mathrm{Cl} 0-7.3) \\
0(0.0 \%, \mathrm{Cl} 0-7.3)\end{array}$ & $\begin{array}{l}1(16.7, \mathrm{Cl} 0.42-64.1) \\
1(16.7, \mathrm{Cl} 0.42-64.1) \\
1(16.7, \mathrm{Cl} 0.42-64.1) \\
1(16.7, \mathrm{Cl} 0.42-64.1) \\
\\
0(0.0, \mathrm{Cl} 0.0-46.0) \\
0(0.0, \mathrm{Cl} 0.0-46.0) \\
0(0.0, \mathrm{Cl} 0.0-46.0) \\
0(0.0, \mathrm{Cl} 0.0-46.0)\end{array}$ & $\begin{array}{l}0(0.0, \mathrm{Cl} 0.0-21.0) \\
0(0.0, \mathrm{Cl} 0.0-21.0) \\
0(0.0, \mathrm{Cl} 0.0-21.0) \\
0(0.0, \mathrm{Cl} 0.0-21.0) \\
\\
0(0.0, \mathrm{Cl} 0.0-21.0) \\
0(0.0, \mathrm{Cl} 0.0-21.0) \\
0(0.0, \mathrm{Cl} 0.0-21.0) \\
0(0.0, \mathrm{Cl} 0.0-21.0)\end{array}$ \\
\hline
\end{tabular}

Table 4: Dopamine agonist prescription in pregnancy 
Table 5: Pregnancy Outcomes

\begin{tabular}{|c|c|c|c|c|c|c|c|c|}
\hline & $\begin{array}{l}\text { Macroprolactinom } \\
\mathrm{N}=47\end{array}$ & $\begin{array}{l}\text { Nonfunctioning } \\
\text { pituitary } \\
\text { adenomaN=16 }\end{array}$ & & $P$ value & $\begin{array}{l}\text { UKOSS } \\
\text { control } \\
\mathrm{N}=\mathbf{2 2 0 5}\end{array}$ & $\mathrm{RR}^{2}$ & ONS** & $\mathbf{R R}^{3}$ \\
\hline \begin{tabular}{|l|} 
Prematurity (<37 \\
weeks) \\
no. (\%) \\
$(95 \% \mathrm{Cl})$
\end{tabular} & $\begin{array}{l}2 / 46(4.3) \\
(0.53-14.8)\end{array}$ & $\begin{array}{l}2(12.5) \\
(1.6-38.3)\end{array}$ & $\begin{array}{l}0.35 \\
(0.053- \\
2.27)\end{array}$ & 0.27 & $\begin{array}{l}144 / 2200 \\
(6.5) \\
(5.5-7.7)\end{array}$ & $\begin{array}{l}0.99 \\
(0.38- \\
2.58)\end{array}$ & $\begin{array}{l}151,082 / 2,144,019 \\
(7.05) \\
(7.01-7.08)^{4}\end{array}$ & $\begin{array}{l}0.92 \\
(0.35-2.36)\end{array}$ \\
\hline \begin{tabular}{|l|} 
Pregnancy \\
induced \\
Hypertension \\
no. $(\%)$ \\
$(95 \% \mathrm{Cl})$ \\
\end{tabular} & $\begin{array}{c}4 / 47(8.5) \\
(2.36-20.4)\end{array}$ & $\begin{array}{l}1(6.3) \\
(0.16-301.2)\end{array}$ & $\begin{array}{l}1.36 \\
(0.16- \\
11.3)\end{array}$ & 1.00 & * & --- & $\begin{array}{l}90,038 / 2,008,386 \\
(4.48) \\
(4.45-4.51)\end{array}$ & $\begin{array}{l}1.77 \\
(0.76-4.10)\end{array}$ \\
\hline \begin{tabular}{|l} 
Pre- eclampsia \\
no. $(\%)$ \\
$(95 \% \mathrm{Cl})$
\end{tabular} & $\begin{array}{l}2 / 47(4.3) \\
(0.52-14.5)\end{array}$ & $\begin{array}{l}0 / 15 \\
(0) \\
(0-0.22)\end{array}$ & NC & 1.00 & $*$ & --- & $*$ & --- \\
\hline \begin{tabular}{|l|} 
Stillborn \\
no. (\%) \\
$(95 \%$ Cl)
\end{tabular} & $\begin{array}{l}0 / 44(0) \\
(0-0.08)\end{array}$ & $\begin{array}{l}1(6.3) \\
(0.16-30.2)\end{array}$ & NC & 0.27 & $\begin{array}{l}11 / 2205 \\
(0.50) \\
(0.25- \\
0.89)\end{array}$ & $\begin{array}{l}4.01 \\
(0.53- \\
30.5)\end{array}$ & $\begin{array}{l}11,083 / 2,176,752 \\
(0.509) \\
(0.50-0.52)\end{array}$ & $\begin{array}{l}3.22 \\
(0.46-22.5)\end{array}$ \\
\hline
\end{tabular}

* These data were not available for comparison. However, pre-eclampsia is believed to affect 2-8\% pregnant women in the UK [26])

** Data only available including multiple pregnancies. Comparisons may be affected

$\mathrm{NC}=$ Data could not be calculated

${ }^{1}$ Comparison between macroprolactinoma and Nonfunctioning pituitary adenomawith $95 \% \mathrm{Cl}$

${ }^{2}$ Comparison between UKOSS controls and those with macroprolactinoma or Nonfunctioning pituitary adenomawith $95 \%$ $\mathrm{Cl}$

${ }^{3}$ Comparison between ONS controls and those with macroprolactinoma or Nonfunctioning pituitary adenomawith $95 \% \mathrm{Cl}$

${ }^{4}$ ONS data was obtained from 2009, 2010 and 2011 statistics 
Box 1: Presenting symptoms of pituitary apoplexy and tumour expansion in pregnant women

\section{Symptoms of pituitary apoplexy:}

Headache

Visual disturbance

Ophthalmoplegia

Nausea and vomiting

Altered consciousness

Symptoms of pituitary tumor expansion:

Headache

Visual disturbance

Ophthalmoplegia

Altered consciousness

Diabetes insipidus

\section{Box 2: Management of macroprolactinoma in pregnancy}

\section{Endocrine Society guideline:}

Continue dopaminergic therapy in pregnancy in selected patients based upon:

- Proximity to the optic chiasm

- Whether they have had previous surgery or radiotherapy

Close surveillance including regular clinical review and formal visual field testing

If symptoms of tumour expansion therapeutic options include:

- Reinstitution of dopamine agonist therapy

- Surgical debulking

- If the pregnancy is near term, deliver is an option prior to neurosurgical intervention

\section{Pituitary Society guideline:}

Due to the $20-30 \%$ risk of symptomatic expansion, options are either to:

- Continue dopamine agonist throughout pregnancy

- Ensure close surveillance if dopamine agonists are stopped in early pregnancy

Recommended management if symptomatic tumour expansion occurs:

- Assess using MRI

- Restart dopamine agonist if the tumour has grown significantly

- If no response to reinstitution of dopamine agonist therapy, consider delivery or surgery 